\title{
In vitro susceptibility of Staphylococcus aureus to thrombin-induced platelet microbicidal protein-1 (tPMP-1) is influenced by cell membrane phospholipid composition and asymmetry
}

Correspondence

Arnold S. Bayer

bayer@humc.edu

Received 4 October 2006

Revised 14 November 2006

Accepted 14 November 2006
Kasturi Mukhopadhyay, ${ }^{1}$ William Whitmire, ${ }^{1}$ Yan O. Xiong, ${ }^{1,2,3}$ Jaime Molden, ${ }^{2}$ Tiffanny Jones, ${ }^{1}$ Andreas Peschel, ${ }^{4}$ Petra Staubitz, ${ }^{4}$ Jill Adler-Moore, ${ }^{5}$ Peter J. McNamara, ${ }^{6}$ Richard A. Proctor, ${ }^{6}$ Michael R. Yeaman ${ }^{1,2,3}$ and Arnold S. Bayer ${ }^{1,2,3}$

\author{
${ }^{1}$ The LA Biomedical Research Institute at Harbor-UCLA Medical Center, Torrance, CA, USA \\ ${ }^{2}$ The Department of Medicine, Harbour-UCLA Medical Center, Torrance, CA, USA \\ ${ }^{3}$ The David Geffen School of Medicine at UCLA, Los Angeles, CA, USA \\ ${ }^{4}$ Cellular and Molecular Microbiology, Medical Microbiology and Hygiene, University of \\ Tübingen, Tübingen, Germany \\ ${ }^{5}$ Department of Microbiology, California State Polytechnical State University-Pomona, Pomona, \\ CA, USA \\ ${ }^{6}$ Department of Medical Microbiology and Immunology, University of Wisconsin, Madison, WI, \\ USA
}

\begin{abstract}
Thrombin-induced platelet microbicidal proteins (e.g. tPMP-1) are small cationic peptides released from mammalian platelets. As the cytoplasmic membrane (CM) is a primary target of tPMPs, distinct CM characteristics are likely to affect the cells' susceptibility profiles. In Staphylococcus aureus, CM surface charge and hydrophobicity are principally determined by the content and distribution of its three major phospholipid (PL) constituents: negatively charged phosphatidylglycerol (PG) and cardiolipin (CL) and positively charged lysyl-PG (LPG). PL composition profiles, and inner vs outer $\mathrm{CM}$ leaflet $\mathrm{PL}$ distributions, were compared in an isogenic tPMP-susceptible (tPMP ${ }^{S}$ ) and -resistant $\left(\mathrm{tPMP}^{\mathrm{R}}\right.$ ) S. aureus strain pair (ISP479C vs ISP479R respectively). All PLs were asymmetrically distributed between the outer and inner CM leaflets in both strains. However, in ISP479R, the outer CM leaflet content of LPG was significantly increased vs ISP479C ( $27.3 \pm 11.0 \%$ vs $18.6 \pm 7.0 \%$ respectively; $P=0.05)$. This observation correlated with reduced binding of the cationic proteins cytochrome $c$, poly-L-lysine, tPMP-1 and the tPMP-1-mimetic peptide, RP1, to tPMP-1 ${ }^{R}$ whole cells and to model liposomal CMs with LPG content and distribution similar to that of $\mathrm{tPMP}-1^{\mathrm{R}}$ strains. Collectively, selected $\mathrm{CM}$ parameters correlated with reduced staphylocidal capacities of tPMP-1 against certain S. aureus strains, including relative increases in outer $\mathrm{CM}$ leaflet positive charge and reduced surface binding of cationic molecules. These findings offer new insights into mechanisms of antimicrobial peptide susceptibility and resistance in $S$. aureus.
\end{abstract}

Abbreviations: $\mathrm{BH}$, brain heart infusion; $\mathrm{C}_{6}-\mathrm{NBD}-\mathrm{PG}, 1-$ palmitoyl-2-[(6NBD-amino)hexanoyl-sn-glycero-3-[phospho-rac-(1-glycerol)]ammonium salt; CAP, cationic antimicrobial peptide; $\mathrm{CL}$, cardiolipin; $\mathrm{CM}$, cytoplasmic membrane; DP-LPG, 1,2-dipalmitoyl-sn-glycerol-3-(phospho-3-lysylglycerol); DPPG, 1,2-dipalmitoyl-sn-glycero-3-phosphoglycerol; LPG, lysylphosphatidylglycerol; NAO, 10-N-nonyl acridine orange; NBD, 7-nitro2,1,3-benzoxadiazol-4-yl; PG, phosphatidylglycerol; PL, phospholipid; PMP, platelet microbicidal protein; tPMP-1, thrombin-induced PMP-1; tPMP $^{\mathrm{S}}$, tPMP-susceptible; tPMP ${ }^{\mathrm{R}}$, tPMP-resistant.

\section{INTRODUCTION}

Mammalian platelets release a cadre of cationic antimicrobial peptides (CAPs), termed platelet microbicidal proteins (PMPs), which kill many important blood-borne pathogens including Staphylococcus aureus (Bayer et al., 1998, 2000; $\mathrm{Wu}$ et al., 1994; Yeaman et al., 1997, 1998). The bestcharacterized PMP is thrombin-induced PMP-1 (tPMP-1), a $\sim 8 \mathrm{kDa}$ peptide released in response to physiological stimuli at damaged or infected endovascular surfaces (Koo 
et al., 1996a, b, 1999; Xiong et al., 1999, 2002; Yeaman et al., 1998). A large body of evidence suggests that tPMP-1 plays a key role in host defence against endovascular infections, such as infective endocarditis (Dhawan et al., 1997; Fowler et al., 2000; Kupferwasser et al., 2002; Wu et al., 1994; Yeaman, 1997).

Our previous studies have identified the $S$. aureus cytoplasmic membrane $(\mathrm{CM})$ as an initial target for the microbicidal actions of tPMPs. These peptides cause rapid permeabilization of the $\mathrm{CM}$ and the eventual death of susceptible bacteria in vitro (Koo et al., 1997, 2001). Thus, the intrinsic properties of the $S$. aureus $\mathrm{CM}$ may have a significant impact upon the capacity of tPMP-1 to initiate lethality. For example, using isogenic strain pairs, we have recently demonstrated that several engineered mutants that are relatively resistant to the lethal action of tPMP-1 on a tPMP-1-resistant $\left(\right.$ tPMP- $\left.^{\mathrm{R}}\right)$ strain have more fluid CMs than their respective tPMP-1-susceptible $\left(\mathrm{tPMP}^{\mathrm{S}}{ }^{\mathrm{S}}\right)$ parental strains (Bayer et al., 2000).

The net charge of the $S$. aureus cell envelope affects the cells' susceptibility profile towards CAPs (Peschel, 2002). For example, the extent of D-alanylation of cell wall teichoic acids contributes to the relative positive charge of the $S$. aureus cell surface, and correlates with in vitro resistance to a number of CAPs (Peschel, 2002; Peschel et al., 1999). In addition, several laboratories have documented that the overall S. aureus CM PL composition also contributes to the microbial surface charge, and substantially influences the net antimicrobial activity of CAPs (Koprivnjak et al., 2002; Kristian et al., 2003; Nishi et al., 2004; Peschel, 2002; Peschel et al., 1999; Xiong et al., 2005). CM charge in S. aureus is principally determined by the relative contents of its three major PLs: the two negatively charged PLs, phosphatidylglycerol (PG) and cardiolipin (CL); and the positively charged PL, lysyl-PG (LPG) (Peschel et al., 2001). A related characteristic that may well affect CAP susceptibilities is the distribution of PLs within the CM. It is well known that PLs are asymmetrically distributed in the outer and inner CM leaflets in both prokaryotes and eukaryotes (Pomorski et al., 2004; Tannert et al., 2003). We hypothesized that a PL distribution yielding a relatively more positively charged outer vs inner $\mathrm{CM}$ leaflet might be associated with reduced susceptibility to the cationic tPMP1 through reduced electrostatic affinities. This hypothesis has been verified in the current study through investigation of binding of two non-specific cationic proteins (cytochrome $c$ and poly-L-lysine) as well as for three specific CAPs (tPMP-1, the tPMP peptide mimetic, RP1, and the human neutrophil defensin, hNP-1).

For this investigation, we utilized a well-characterized isogenic $S$. aureus strain pair, comprising a tPMP- $1^{\mathrm{S}}$ parental strain, ISP479C, and its isogenic tPMP- $1^{\mathrm{R}}$ counterpart, ISP479R. In addition, we have developed, and report here for the first time, three novel chromatographic and flow cytometric assays to delineate PL asymmetry within the $S$. aureus $\mathrm{CM}$.
This study was presented in part at the 105th General Meeting of the American Society for Microbiology; Atlanta, GA; June 7th, 2005 (abstract \#A-002).

\section{METHODS}

Bacterial strains. An isogenic tPMP-1-susceptible (tPMP- $1^{\mathrm{S}}$, ISP479C) and tPMP-1-resistant (tPMP- $1^{\mathrm{R}}$, ISP479R) S. aureus strain pair was used in this study. The construction of ISP479R by transposon mutagenesis, and the delineation of the gene disruption in this construct $(s n o D)$, are described elsewhere (Bayer et al., 2006; Dhawan et al., 1997). These strains are indistinguishable in terms of a number of phenotypic characteristics, including coagulase production and fibrinogen binding (Dhawan et al., 1997). The in vitro susceptibility testing of the isogenic strain pair against tPMP-1 has also been previously reported (Dhawan et al., 1997). These studies revealed that the mean percentage survival of strains ISP479C and ISP479R $\left(10^{3}\right.$ c.f.u. inoculum) after $2 \mathrm{~h}$ exposure to tPMP-1 at $2 \mu \mathrm{g} \mathrm{ml}^{-1}$ was $20 \%$ and $75 \%$, respectively (Dhawan et al., 1997). The arbitrary break point for $\mathrm{tPMP}-1^{\mathrm{R}}$ is $50 \%$ survival (Wu et al., 1994). Complementation of snoD reinstated near parental-level susceptibility (35\% survival; Dhawan et al. 1997). Moreover, the CM fluidity characteristics of this strain set revealed that the tPMP- $1^{\mathrm{R}}$ strain, ISP479R, has significantly more fluid CMs than the tPMP- 1 S parental strain, ISP479C (Bayer et al., 2006). Complementation reverses the fluidity profiles to parental levels. Thus, as previously reported, the polarization indices for the parental strain and complemented variant were $0.32 \pm 0.02$ and $0.32 \pm 0.01$, respectively, while that for the $t P M P-1^{\mathrm{R}}$ strain, ISP479R, was $0.308 \pm 0.01 \quad(P<0.05$ vs parent and complemented variant; Dhawan et al., 1997). All the above studies utilized vigorous vortexing to ensure singlet organisms for assays.

\section{Phospholipid (PL) analyses}

Extraction, identification and quantification of PLs. PLs were extracted from $S$. aureus by standard methods (Dixit \& Gupta, 1998). Briefly, cells were grown for $18 \mathrm{~h}$ in BHI broth, harvested by centrifugation $\left(3000 \mathrm{~g}, 4{ }^{\circ} \mathrm{C}, 15 \mathrm{~min}\right)$, and washed in buffer A (100 mM potassium phosphate, $5 \mathrm{mM}$ EDTA, pH 7.2) followed by buffer B (100 mM potassium phosphate, $600 \mathrm{mM}$ potassium chloride, $\mathrm{pH} 8.2$ ). Cells $\left(0.6 \mathrm{~g}\right.$ wet weight, $\sim 1 \times 10^{8}$ cells $\mathrm{ml}^{-1}$ ) were suspended in $3 \mathrm{ml}$ buffer $\mathrm{B}$ and transferred to a $25 \mathrm{ml}$ glass conical flask and cooled to $4{ }^{\circ} \mathrm{C}$ with gentle swirling. The suspension was centrifuged and the pellet washed with buffer $\mathrm{C}(200 \mathrm{mM}$ potassium acetate, $600 \mathrm{mM}$ potassium chloride, $\mathrm{pH} 4.5)$ at $4{ }^{\circ} \mathrm{C}$.

The cell pellet was then extracted using 2:1 (v/v) chloroform/ methanol, followed by washing with $0.9 \% \mathrm{NaCl}$ to remove non-lipid contaminants. The extracted organic layer was evaporated to dryness under nitrogen and stored at $-20{ }^{\circ} \mathrm{C}$ until analysis. The major PL species, PG, CL and LPG, were separated by two-dimensional thinlayer chromatography (2D-TLC) using Silica 60 F254 HPTLC plates (Merck) and subsequently developed with chloroform/methanol/25\% ammonium hydroxide $(65: 25: 6$, by vol.) in the vertical orientation, and chloroform/acetone/acetic acid/methanol/water (45:16:9:8:4, by vol.) in the horizontal orientation as detailed elsewhere (Dogra et al., 1999). LPG (positively charged) was identified by ninhydrin staining (Peschel et al., 2001). PG, CL and other minor PLs were visualized by exposure of the TLC plate to iodine vapour. All PLs were purchased from Avanti Polar Lipids and used as internal standards on the 2D-TLC plates.

For quantitative analysis, isolated PLs were individually recovered from TLC plates, and digested at $180{ }^{\circ} \mathrm{C}$ for $3 \mathrm{~h}$ with $0.3 \mathrm{ml} 70 \%$ perchloric acid. The digested samples were incubated with a colorimetric reagent 
[10\% ascorbic acid, $2.5 \%$ ammonium molybdate, $5 \%$ perchloric acid $\left(1: 1: 8\right.$, by vol.)] for $2 \mathrm{~h}$ at $37^{\circ} \mathrm{C}$, and PLs quantified spectrophotometrically at $660 \mathrm{~nm}$. The content of each PL species was expressed as a percentage of total PL content. All assays were performed a minimum of five times on separate days.

LPG distribution. Fluorescamine, a fluorescent probe which specifically labels CM surface-exposed (outer leaflet), positively charged amino-PLs, was used to assay for CM LPG distribution (Balasubramanian \& Gupta, 1996; Dixit \& Gupta, 1998). Fluorescamine labelling was carried out by a modification of the 2D-TLC protocol above. To the cell pellet, $90 \mu$ fluorescamine solution $(0.52 \mathrm{M})$ in dehydrated dimethylsulfoxide was added drop-wise, and then subjected to 2D-TLC as described above. Fluorescamine labelling of outer-leaflet LPG was detected by using a UV detector (365 nm excitation). Once bound to LPG, fluorescamine alters its mobility characteristics, and its ability to be detected by ninhydrin staining is attenuated (Huijbregts et al., 1998). Inner-leaflet LPG was detected by ninhydrin staining.

After detection of the fluorescamine-labelled LPG, its relative content (normalized with respect to total PL and to total LPG) was quantified by the colorimetric assay above. All assays were performed a minimum of five times on separate days.

Cardiolipin (CL) distribution by NAO labelling. For measurement of CL asymmetry, the fluorescent dye 10-N-nonyl acridine orange (NAO), was used. Following exposure to $S$. aureus cells, two NAO molecules bind to the two phosphate groups of the CL molecule, resulting in the shifting of NAO fluorescence from $525 \mathrm{~nm}$ (monomeric form of the dye) to $640 \mathrm{~nm}$ (dimeric form of the dye) (Gallet et al., 1995, 1997; Petit et al., 1992, 1994). NAO will bind initially to the outer CM leaflet CL. Following saturation of outer leaflet CL, the probe then initiates binding to CL distributed in inner CM leaflet regions until full saturation (Gallet et al., 1997; Petit et al., 1994).

Mid-exponential phase cells were adjusted spectrophotometrically to $10^{6}$ cells $\mathrm{ml}^{-1}$ in HEPES buffer containing $10 \% \mathrm{BHI}$ broth and kept at $4{ }^{\circ} \mathrm{C}$. Increasing amounts of NAO $(1-5 \mu \mathrm{M})$ were added to the cell suspension, which was then incubated for $20 \mathrm{~min}$ at $4{ }^{\circ} \mathrm{C}$. NAO binding to CL was measured by flow cytometry using a FACScalibur [Becton-Dickinson; excitation $488 \mathrm{~nm}$, emission $\geqslant 620 \mathrm{~nm}$ long-pass filter (FL-4 channel)]. For each analysis, 10000 cells were acquired and plotted against forward light scatter (flow rate, 200 cells s $^{-1}$ ). All assays were performed a minimum of two times on separate days. Quantitative culture was done to ensure that the interaction of NAO with the $S$. aureus CM did not alter viability.

Phosphatidylglycerol (PG) distribution. Highly fluorescent 7-nitro2,1,3-benzoxadiazol-4-yl-lipid (NBD-lipid) analogues are widely used to examine PL distribution and transport (Balch et al., 1994; Dekkers et al., 2000, Grant et al., 2001; Hrafnsdottir et al., 1997; McIntyre \& Sleight, 1991). To investigate the distribution of PG, $\mathrm{C}_{6^{-}}$ NBD-PG was introduced into the CM of $S$. aureus cells by modification of the methods of Pomorski et al. (1996). At equilibrium, the distribution of the $\mathrm{C}_{6}$-NBD-PG probe closely reflects the overall distribution of the specific endogenous CL (Dekkers et al., 2000; Kol et al., 2004). Extensive pilot studies were performed with flow cytometry to define the optimal assay conditions. We determined that exposing S. aureus cells $\left(2 \times 10^{7}\right.$ cells $)$ to $\mathrm{C}_{6}-\mathrm{NBD}-\mathrm{CL}$ at $5 \mathrm{nmol}$ per assay for $30 \mathrm{~min}$ yielded maximal labelling (representing saturation of both inner and outer $\mathrm{CM}$ leaflets). The ethanolic solution of $\mathrm{C}_{6^{-}}$ NBD-PG was added ( $1 \%$ of the final volume) to the desired volume of cell suspension in HEPES buffer containing $10 \%$ BHI broth with vigorous vortexing. Before labelling, the cell suspension was cooled to $4{ }^{\circ} \mathrm{C}$ to minimize $\mathrm{C}_{6}$-NBD-PG internalization. Next, the fluorescence of cell suspensions was measured by flow cytometry until saturation of fluorescence intensity occurred. The NBD moiety was excited at $488 \mathrm{~nm}$ with an argon laser, and the resulting fluorescence emission was collected through a $525 \mathrm{~nm}$ band pass filter (FL-1 channel). To quantify the specific outer leaflet distribution of $\mathrm{C}_{6}$ NBD-PG, NBD fluorescence was quenched by the CM-impermeant molecule sodium dithionite (final concentration $25 \mathrm{mM}$; Angeletti \& Nichols, 1998; Balch et al., 1994; McIntyre \& Sleight, 1991; Pomorski et al., 1996). Fluorescence remaining after dithionite treatment reflects the amount of $\mathrm{C}_{6}$-NBD-PG residing in the inner $\mathrm{CM}$ leaflet (McIntyre \& Sleight, 1991).

Cytochrome $\boldsymbol{c}$ and poly-L-lysine binding. Cytochrome $c$ is a cationic protein derived from equine heart. It has been previously used to estimate the relative surface charge of the cell envelope of isogenic S. aureus strain pairs (Peschel et al., 1999). Poly-L-lysine is a polycationic molecule which is widely used to study the interaction between cationic peptides and charged bilayer membranes (Rossetti et al., 2004). We performed cytochrome $c$ and FITC-labelled poly-Llysine binding assays (Sigma) according to a previously described method (Peschel et al., 1999). In brief, S. aureus cells were grown overnight, and then washed twice with MOPS buffer $(20 \mathrm{mM}, \mathrm{pH} 7$ for cytochrome $c$ ) and HEPES buffer $(20 \mathrm{mM}, \mathrm{pH} 7.25$ for poly-Llysine). The cells were suspended in the corresponding buffer to a final $\mathrm{OD}_{578}$ of 7 for cytochrome $c$ and $\mathrm{OD}_{578}$ of 0.1 for poly-Llysine. The suspension was incubated with $0.5 \mathrm{mg}$ cytochrome $c \mathrm{ml}^{-1}$ or $10 \mu \mathrm{g}$ poly-L-lysine $\mathrm{ml}^{-1}$ for $10 \mathrm{~min}$ in the corresponding buffer and centrifuged (for liposome binding assays, see below). The amount of cytochrome $c$ remaining in the supernatant (i.e. unbound) was determined spectrophotometrically at $530 \mathrm{~nm}$, and the amount of poly-L-lysine remaining in the supernatant was determined fluorometrically (excitation at $500 \mathrm{~nm}$ and emission at $530 \mathrm{~nm}$ ) without or with bacterial exposure. The quantity of bound molecule was calculated from the difference between these values. The lower the amount of bound cytochrome $c /$ poly-L-lysine, the more positively charged the $S$. aureus cell envelope (Peschel et al., 1999).

\section{Peptide binding to $S$. aureus whole cells and model membranes}

To differentiate the initial binding of tPMP-1 to the whole $S$. aureus cell (a combination of cell envelope and $\mathrm{CM}$ binding) from binding exclusively to the target CM, we utilized two complementary assays (whole-cell vs liposomal binding). For liposomal binding assays, we utilized purified tPMP-1 (prepared by RP-HPLC, Yeaman et al., 1997) and hNP1 (Peptide International) as a comparator CAP. For whole-cell binding assays, the binding of tPMP-1 to cells could not be done by the radial diffusion assay (see below) due to lack of peptide diffusibility through agar (Xiong et al., 2006). Moreover, the protein-spectrophotometric assay described below for tPMP-1: liposome interactions could not be utilized for tPMP- 1 : whole-cell assays due to interference by secreted exoproteins within whole-cell supernatants. Finally, the amount of RP-HPLC-purified tPMP-1 required for the whole-cell binding assays is prohibitive. Thus, to substantiate our findings, we instead utilized the synthetic tPMP-mimetic peptide RP1, which is an 18-amino acid peptide (N-ALYKK ${ }^{5}$ FKKKL $^{10}{ }^{10}$ KSLK $^{15}$ RLG-C; mass $2163 \mathrm{Da}$ ) modelled upon the $\alpha$-helical C-terminal microbicidal domain of tPMP-1 (Yeaman et al., 2002; Yount et al., 2004). RP-1 precisely recapitulates the mechanism of action of the native molecule (Xiong et al., 2006). Also, as opposed to tPMP-1, this peptide diffuses readily through nutrient agar. RP-1 was synthesized with a symphony multiplex synthesizer (Rainin, Woburn, MA, USA) and authenticated by mass spectroscopy and amino acid analysis as previous described (Yeaman et al., 2002). Purified RP-1 was lyophilized and resuspended in sterile $0.01 \%$ acetic acid for use in the microbiological assays.

Peptide binding to whole cells. We performed whole-cell binding assays by a modification of a radial diffusion assay previously 
described (Takemura et al., 1996; Yeaman et al., 2002). Briefly, an agar diffusion plate was prepared by first seeding $10^{6}$ c.f.u. $\mathrm{ml}^{-1}$ of Bacillus subtilis (ATCC 6633), a tPMP-1-hypersusceptible indicator strain (Yeaman et al., 1997), into $20 \mathrm{ml}$ 2-( $\mathrm{N}$-morpholino)ethanesulfonic acid (MES) agar supplemented with $1 \%$ molecular-grade agarose and $0.03 \%$ glucose (Sigma). This reaction mixture was then poured into $95 \times 15 \mathrm{~mm}$ Petri dishes. After allowing agar solidification, approximate $50 \mu \mathrm{l}$ wells (evenly spaced) were cut with a sterile instrument. For constructing the RP1 and hNP-1 standard curves, a range of peptide concentrations was added to the wells and allowed to incubate in each well for $3 \mathrm{~h}$ at $37^{\circ} \mathrm{C}$, then $\mathrm{BHI}$ agar was overlain. After the agar overlay had solidified, plates were incubated for $18 \mathrm{~h}$ at $37^{\circ} \mathrm{C}$. Zone sizes $(\mathrm{mm})$ were measured using the SpotDense software within the FluorChem 8900 Imaging System (Alpha Innotech). The assay sensitivity was $1 \mu \mathrm{g} \mathrm{ml}^{-1}$. For determining peptide binding to whole cells, each strain was grown for $18 \mathrm{~h}$ in $\mathrm{BHI}$ broth at $37^{\circ} \mathrm{C}$, washed, and resuspended to a final inoculum of $10^{8}$ c.f.u. $\mathrm{ml}^{-1}$. Both peptides (final concentration of $40 \mu \mathrm{g} \mathrm{ml}^{-1}$ in $0.01 \%$ acetic acid) were then added to each organism and incubated for $10 \mathrm{~min}$ at room temperature, followed by centrifugation at 10000 r.p.m. Supernatants were removed, lyophilized, and stored at $4{ }^{\circ} \mathrm{C}$ until assayed by the radial diffusion assay described above. Supernatant peptide concentrations were determined by achievable zone sizes referable to the above standard curve. Three independent assays were performed on different days. The amount of peptide bound to each $S$. aureus whole cell preparation was then calculated and displayed as peptide bound $\left(\mu \mathrm{g} \mathrm{ml}^{-1} ; \pm \mathrm{SD}\right)$.

Peptide binding to model liposomes. Liposomes containing synthetic LPG (DP-LPG), DPPG and bovine-CL were prepared as previously described (Xiong et al., 2005). We formulated liposomes of the following compositions to reflect a proportional range of the three major PLs in $S$. aureus whole cells: LPG:PG:CL of $0: 7: 1$, $2: 7: 1$, and $3: 7: 1$. All lipid constituents were dissolved in chloroform:methanol $(1: 1)$, and dried under a stream of nitrogen followed by desiccation overnight. The lipid film was hydrated with HEPES buffer containing $9 \%$ sucrose and then sonicated for $4 \mathrm{~min}$ and used within 2-3 days. Liposome stability was verified by calcein retention as previously described (data not shown) (Xiong et al., 2005). We confirmed that added LPG (the positively charged PL within the liposomal membrane) asymmetrically distributed within liposomes similar to its behaviour in whole cells, using the fluorescamine assay as described above. Thus, at liposomal formulations of LPG:PG:CL of $2: 7: 1$ and $3: 7: 1, \sim 30 \%$ of LPG was distributed to the outer membranes (data not shown).

For cytochrome $c$ and poly-L-lysine binding to model membranes, we followed essentially the same protocols as above for whole cells. We used $0.5 \mathrm{mg} \mathrm{ml}^{-1}$ liposomal concentrations for the binding assays. For the peptide-binding assays, a standard curve correlating each peptide concentration with spectrophotometric signals $(595 \mathrm{~nm})$ was established by employing a Coomassie-Bradford kit (Pierce) to determine the concentration of soluble peptide. We then added varying quantities of both peptides to liposomal solutions $\left(0.5 \mathrm{mg} \mathrm{ml}^{-1}\right)$ and incubated for $10 \mathrm{~min}$ at room temperature, followed by ultracentrifugation at 30000 r.p.m. for $40 \mathrm{~min}$ to pellet the liposome-peptide aggregates (Satchell et al., 2003). The concentration of soluble (i.e. unbound) peptide in the supernatant was determined spectrophotometrically from the standard curve. The quantity of bound peptide (Peptide ${ }_{b}$ ) was calculated from the differences between the initial peptide concentration and that remaining in the supernatant. Total bound peptide (Peptide ${ }_{\mathrm{T}}$ ) was calculated similarly as the highest concentration of peptide used (Moore et al., 1986).

Statistical analyses. Data were analysed by the Kruskal-Wallis analysis of variance with corrections made for multiple comparisons where appropriate. Results are reported as means $\pm \mathrm{SD}$. A $P$ value $\leqslant 0.05$ was considered significant.

\section{RESULTS}

\section{PL composition}

We examined the PL content of the ISP479 strain set. No significant differences were observed in the proportions of each specific PL among the tPMP- $1^{\mathrm{S}}$, $\mathrm{tPMP}^{-1}{ }^{\mathrm{R}}$ and complemented variant strain set (Table 1). The snoDrepaired variant of strain ISP479R, ISP479R-comp, exhibited parental-level PL content profiles.

\section{LPG distribution}

The potential asymmetric distribution of LPG (the unique positively charged PL of $S$. aureus) was investigated. As noted in Fig. 1(a), two distinct LPG spots, labelled with either ninhydrin or fluorescamine, were detected. The UVpositive spot represents fluorescamine-labelled LPG (outer CM leaflet LPG), while the unlabelled, inner CM LPG was identified by ninhydrin spraying. As can be seen from Fig. 1(b), LPG was asymmetrically distributed overall (70-80\% in the inner leaflet). Furthermore, the outerleaflet LPG content was significantly higher in the tPMP- ${ }^{\mathrm{R}}$ strain, ISP479R, as compared to the tPMP- $1^{\mathrm{S}}$ counterpart strain, ISP479C $(27.3 \pm 11.0 \%$ vs $18.6 \pm 7.0 \%$, respectively; $P=0.05)$. Complementation of $s n o D$ in strain ISP479R yielded LPG distribution at near-parental levels. Thus, despite overall equivalent total LPG levels in their CMs amongst the strain set, the tPMP- ${ }^{\mathrm{R}}$ construct translocated this positively charged PL to the outer CM leaflet at a significantly higher level than $\operatorname{tPMP}^{-}{ }^{\mathrm{S}}$ strains. This suggested an important linkage between LPG asymmetry, net $\mathrm{CM}$ positive charge and $\mathrm{tPMP}-1^{\mathrm{R}}$ phenotypes.

\section{CL distribution}

When fluorescence was measured at a fixed time after addition of increasing amounts of NAO to bacterial cells, biphasic curves with two plateau levels were observed for

Table 1. Phospholipid content and membrane distribution in parental, $t P M P-1^{R}$ and complemented variant strains

\begin{tabular}{|lcccccc|}
\hline Strain & Inner LPG & Outer LPG $\left(\mathbf{L P G}^{*}\right)$ & \% LPG $^{*}$ vs total LPG & PG & CL & Unknown \\
\hline ISP479C & $16.2 \pm 7.7$ & $3.3 \pm 2.1$ & $18.63 \pm 10.96$ & $65.7 \pm 11.0$ & $10.2 \pm 1.9$ & $4.6 \pm 3.3$ \\
ISP479R & $14.1 \pm 4.3$ & $5.1 \pm 1.5$ & $27.25 \pm 7.03$ & $65.1 \pm 7.20$ & $11.6 \pm 2.7$ & $4.2 \pm 4.1$ \\
ISP479R-comp & $17.1 \pm 1.4$ & $3.6 \pm 1.2$ & $17.24 \pm 5.26$ & $65.5 \pm 2.10$ & $8.6 \pm 1.2$ & $5.4 \pm 1.7$ \\
\hline
\end{tabular}



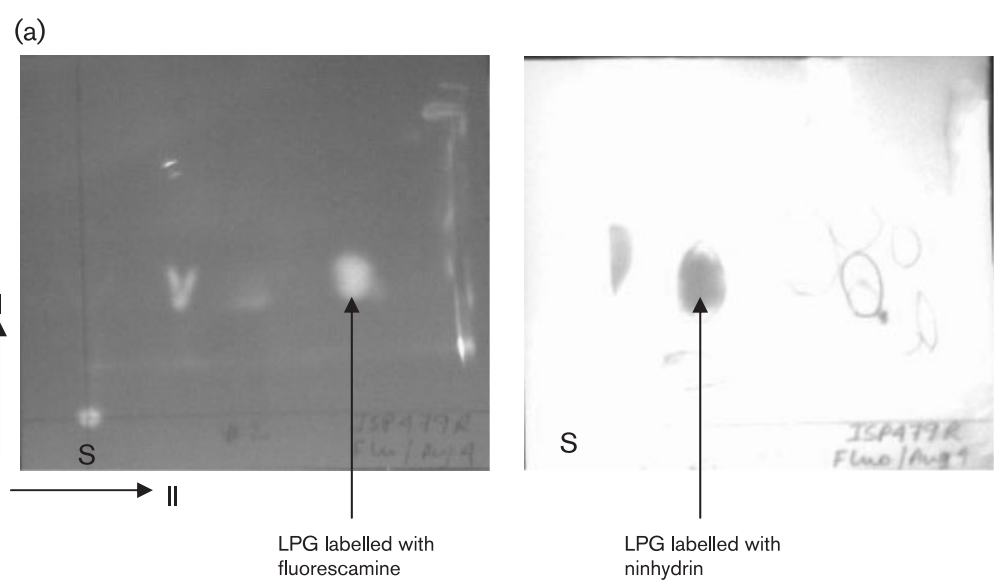

(b)

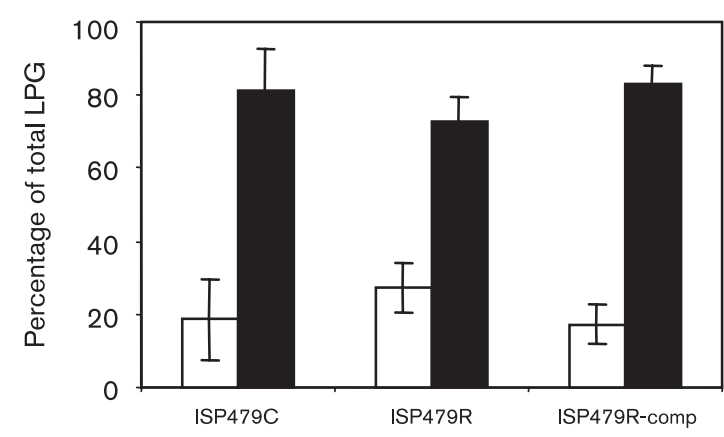

Fig. 1. Membrane phospholipids in a $S$. aureus isogenic strain set. (a) The fluorescamine labelled LPG - outer membrane (detected by UV light) and LPG unlabelled spot - inner membrane (detected by ninhydrin) in 2D TLC. S, sample loading point. (b) Outer membrane (white bars) and inner membrane (black bars) LPG content, in isogenic strain set ISP479C, ISP479R and ISP479R-complemented. both study strains (Fig. 2a). These data confirmed that CL was asymmetrically distributed in the $S$. aureus CM, with $>75 \%$ localized to the outer leaflet (Fig. 2b). It is of interest that for the $\mathrm{tPMP}-1^{\mathrm{R}}$ strain, ISP479R, relatively more CL was localized to the inner CM than seen in the tPMP- $1^{\mathrm{S}}$ strain ( $22 \%$ vs $14 \%$ for ISP479R vs ISP479C; Fig. 2b). However, this difference was not statistically significant.

\section{PG distribution}

Fig. 3 shows the distribution of $\mathrm{C}_{6}-\mathrm{NBD}-\mathrm{PG}$ in the $S$. aureus $\mathrm{CM}$ after labelling the cells with $\mathrm{C}_{6}-\mathrm{NBD}-\mathrm{PG}$ and quenching of outer leaflet $\mathrm{C}_{6}-\mathrm{NBD}-\mathrm{PG}$ using sodium dithionite. PG was also shown to be asymmetrically distributed in the CM of both study strains. Thus, $\sim 75-85 \%$ of this PL species was (a)

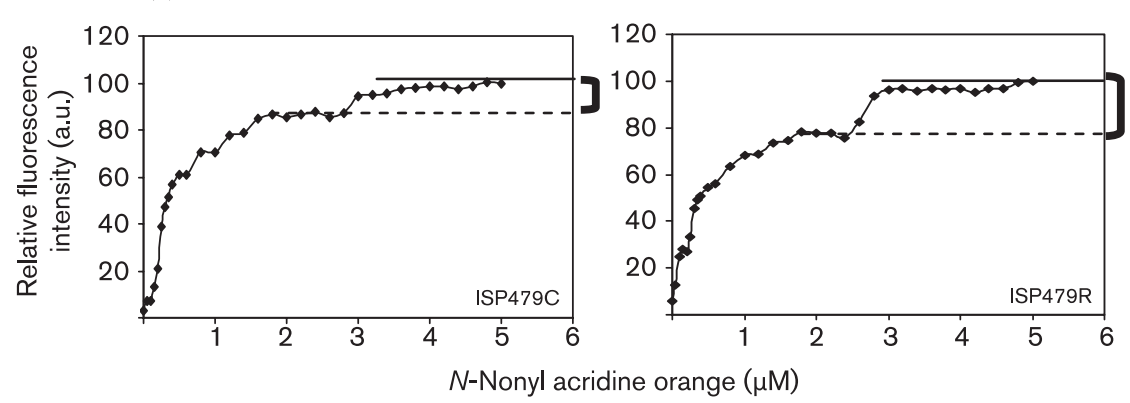

(b)

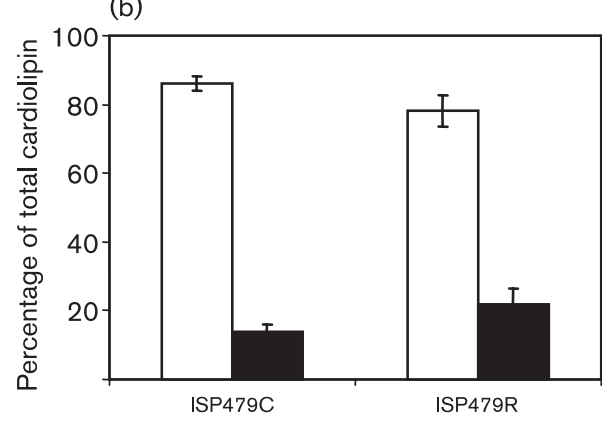

Fig. 2. $\mathrm{CL}$ distribution of $S$. aureus isogenic strain pair as determined by NAO binding, using flow cytometry. (a) The first level (dashed lines) corresponds to the titration of the outer leaflet cardiolipin, and the second level (full lines) corresponds to the total cardiolipin (adjusted to $100 \%$ ). The differences between the two levels (brackets) give the percentage of cardiolipin in the inner leaflet. All data were normalized to a $100 \%$ intensity achieved at the second level. These data represent the means of three separate experiments; error bars are not shown to optimize clarity of display. (b) Percentage of outer-leaflet (white bars) and inner-leaflet (black bars) CL for both strains. Every estimation was done in triplicate, and the values represent mean \pm SD. 


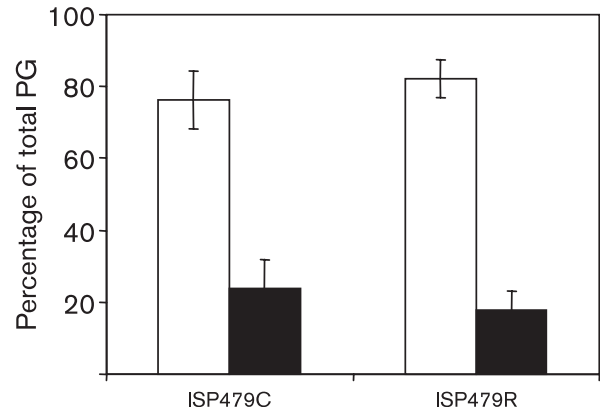

Fig. 3. Dithionite quenching of $\mathrm{C}_{6}-\mathrm{NBD}-\mathrm{PG}$ incorporated in a $S$. aureus strain pair. The percentage of outer (white bars) and inner (black bars) leaflet $\mathrm{C}_{6}-\mathrm{NBD}-\mathrm{PG}$ for strains ISP479C and ISP479R is presented. Every estimation was done in triplicate, and the values represent mean $\pm \mathrm{SD}$.

localized to the outer CM leaflet, with no significant distribution differences between strains.

\section{Cytochrome $c$ and poly-L-lysine binding to whole cells}

Given the above differences in LPG distributions between the tPMP- $1^{\mathrm{S}}$ and tPMP- $1^{\mathrm{R}}$ strains, it was important to quantify the net repulsive impact of such translocation differences. As can be seen from Figs $4(a, b)$, the tPMP- $1^{\text {s }}$ strain, ISP479C, bound significantly higher amounts of the cationic proteins, cytochrome $c$ and poly-L-lysine, than tPMP- $^{\mathrm{R}}$ strain, ISP479R $(P<0.00001$ for both comparisons).

\section{Peptide binding to $S$. aureus whole cells}

Binding of RP- 1 and hNP- 1 to $\mathrm{tPMP}-1^{\mathrm{S}}$ parental strain was substantially greater than that to the tPMP $-1^{\mathrm{R}}$ construct (Fig. 5a, b). Thus, ISP479C bound approximately $54 \%$ and $61 \%$ of RP-1 and hNP-1 in reaction mixtures, respectively, while ISP $479 \mathrm{R}$ bound only approximately $27 \%$ and $38 \%$ of those peptides, respectively ( $P=0.03$ for RP- 1 and 0.013 for hNP-1 respectively).

Thus, enhanced LPG translocation to the outer CM correlated with a net repulsive charge for cationic proteins and peptides.

\section{Cytochrome $c$ and poly-L-lysine binding to model membranes}

As seen in Fig. 6(a, b), there was an inverse relationship between relative LPG content of model liposomal membranes and binding of both cytochrome $c$ and poly-L-lysine. For cytochrome $c$, this difference reached statistical significance $(P<0.01$ comparing the $0: 7: 1$ vs $3: 7: 1$ liposomes). For poly-L-lysine, these differences did not quite reach statistical significance $(P=0.08)$.

\section{Peptide binding to model membranes}

At all concentrations of RP-1, tPMP-1 and hNP-1 tested, the quantity of membrane-associated peptide bound was inversely related to the proportion of liposomal LPG. This effect was especially demonstrable at higher peptide concentrations, with significantly more peptide bound to LPG-free liposomes as compared to liposomes containing LPG : PG:CL of $3: 7: 1(P<0.05)$ (Fig. 7a, b, c).

Therefore, similar to the above results for whole cells, increased amounts of LPG in outer CM leaflets of model liposomes correlated with an enhanced net repulsive impact for cationic proteins and peptides.

\section{DISCUSSION}

CAPs are believed to interact with the CM of microbial pathogens to initiate their lethal effects (Brogden, 2005; Peschel, 2002; Yeaman \& Yount, 2003). For PMPs, this interaction results in CM permeabilization, without depolarization or demonstrable pore formation (Koo et al., 1997, 1999; Yeaman et al., 1998). Our prior studies have principally focused on tPMP-1 as a prototype PMP for several reasons: (i) it is the most abundant PMP from rabbit platelets, a relevant animal model for endovascular pathogenesis (Yeaman 1997; Yeaman et al., 1997); (ii) it is microbicidal in vitro against important bloodstream pathogens, including S. aureus (Yeaman et al., 1997); (iii) the primary and secondary structures of tPMP-1 have been solved, and its tertiary structure has been modelled (Yount et al., 2004); (iv) bacterial strains with reduced susceptibilities to tPMP-1 exhibit enhanced survival in experimental endovascular infection models and in humans with such infections (Bayer et al., 1998; Dhawan et al., 1997; (a)

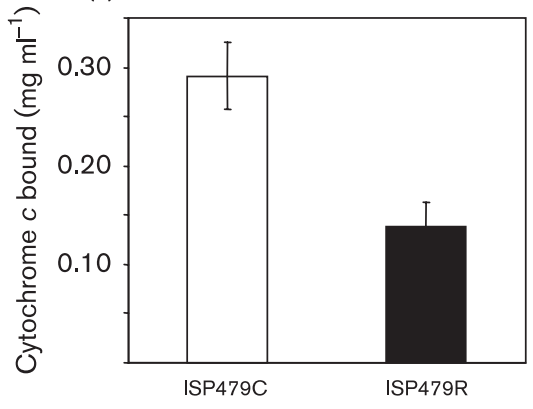

(b)

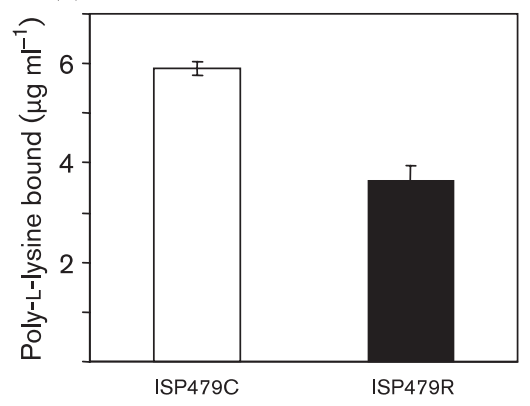

Fig. 4. Interaction of $S$. aureus whole cells with cationic cytochrome $c$ and poly-L-lysine: ISP479C and ISP479R were incubated with cationic cytochrome $c$ (a) and FITC-labelled poly-L-lysine (b), and bound protein was determined as described in Methods. Each assay was done in triplicate on separate days, and the values represent mean \pm SD. 
(a)

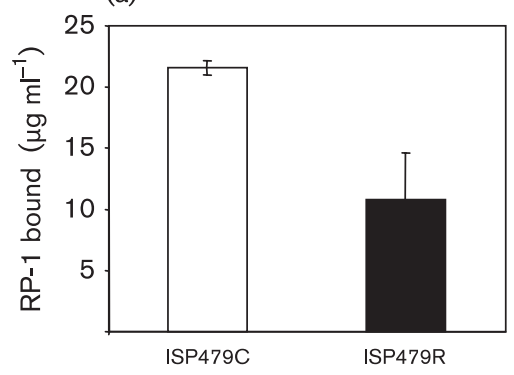

(b)

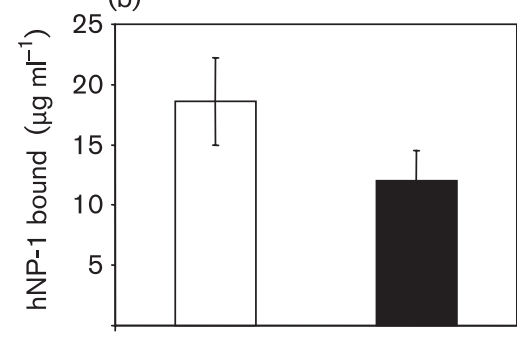

ISP479R
Fig. 5. Peptide binding to whole cells of $S$. aureus. ISP479C and ISP479R $\left(10^{8}\right.$ cells $\left.\mathrm{ml}^{-1}\right)$ were incubated with RP-1 (a) or hNP-1 (b) $\left(40 \mu \mathrm{g} \mathrm{ml}^{-1}\right)$ for $10 \mathrm{~min}$. Each assay was done in duplicate on separate days, and the values represent mean \pm SD.
Fowler et al., 2000; Wu et al., 1994); and (v) tPMP-1, an analogue of human platelet factor-4, represents an archetypal microbicidal chemokine or kinocidin. Thus, this peptide possesses distinct $\mathrm{C}$-terminal microbicidal and $\mathrm{N}$ terminal chemokine domains, with an interposing domain consisting of anti-parallel $\beta$-sheet domains, two of which constitute the $\gamma$-core motif common to other cysteinestabilized kinocidins (e.g. NAP-2; Rantes; PF-4) (Yount et al., 2004).

We have previously studied $S$. aureus strains with reduced in vitro susceptibility to $\mathrm{PMM}-1$ which were derived by distinct methods, including serial passage in tPMP-1 (Yeaman et al., 1994); plasmid carriage of genes encoding efflux pumps for cationic compounds (e.g. QacA) (Kupferwasser et al., 1999); transposon mutagenesis of genes encoding enzymes involved in proton gradient pumps (i.e. snoD) (Bayer et al., 2006; Dhawan et al., 1997); small colony variant
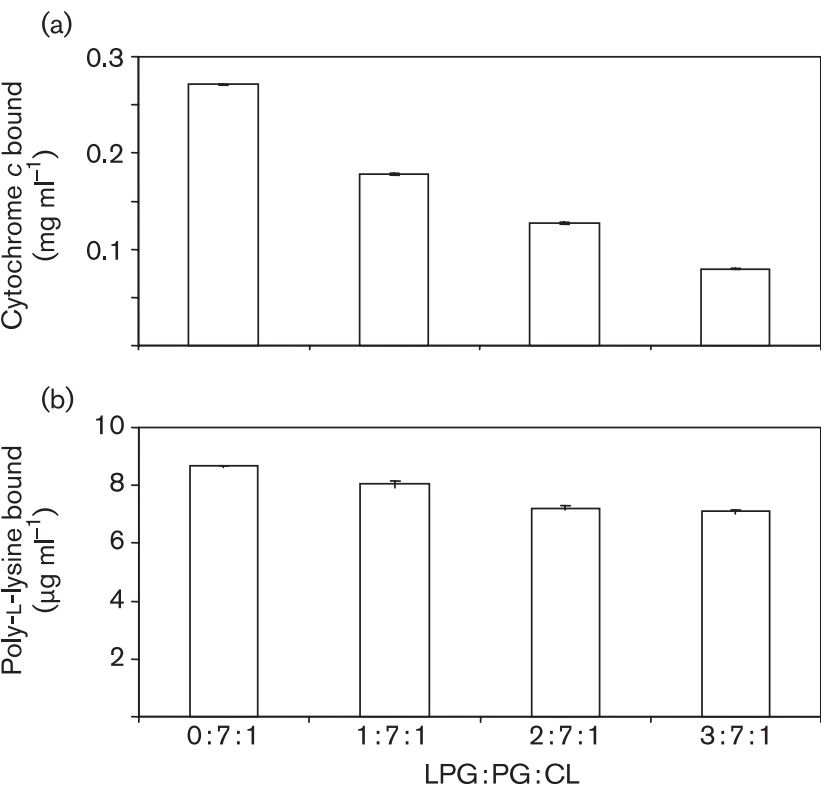

Fig. 6. Cytochrome $c$ and poly-L-lysine binding to model liposomes. Liposomes with different formulations (in molar ratio) of LPG : DPPG : CL, as shown, were incubated with cationic cytochrome $c$ (a) and FITC-labelled poly-L-lysine (b). Each assay was done in triplicate on separate days, and the values represent mean \pm SD. formation (e.g. hemB or menD mutants; Bates et al., 2003); and expression of genes encoding the synthesis and incorporation of positively charged amino acid incorporation into CM phospholipids (PLs) (e.g. mprF encoding lysinylation of PG) (Peschel et al., 2001). Although quite diverse, most of these tPMP- $1^{\mathrm{R}}$ variant strains shared

(a)

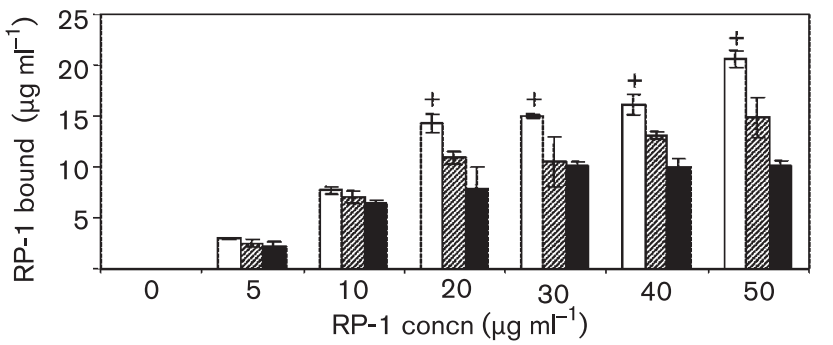

(b)

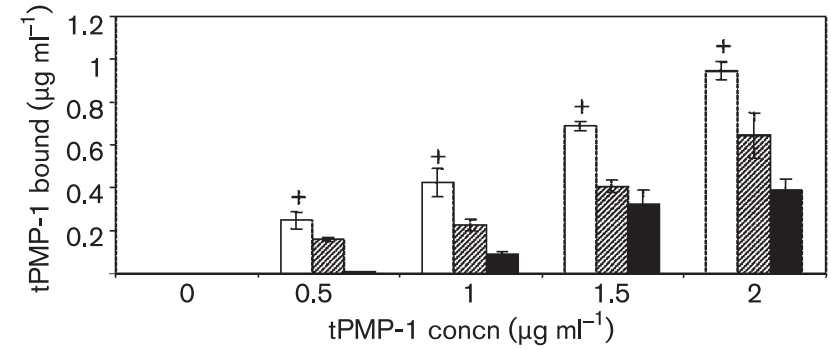

(c)

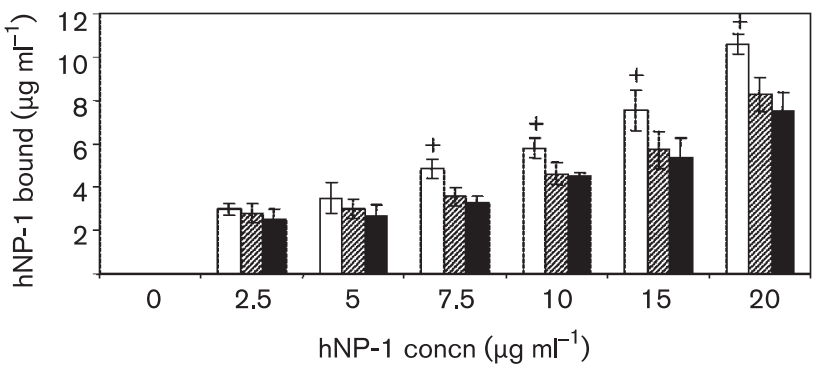

Fig. 7. Peptide binding to model liposomes. (a) RP-1 (b) tPMP-1 and (c) hNP-1: liposomes with different formulations (in molar ratio) of LPG:DPPG:CL (0:7:1, white bars; $2: 7: 1$, hatched bars; or $3: 7: 1$, black bars) were incubated with varying amounts of peptides, and the amounts of bound peptides $\left(\mu \mathrm{g} \mathrm{ml}^{-1}\right.$ ) were calculated as described in Methods.,$+ P<0.05$ comparing DPPG:CL $(7: 1)$ liposome to LPG:DPPG:CL liposome $(3: 7: 1)$. 
common CM alterations, especially enhanced fluidity and/ or reduced transmembrane potential $(\Delta \psi)$. It is of interest that these latter two features are interrelated (i.e. more fluid CMs leak protons, decreasing the net proton-motive force and $\Delta \psi$ of the CM; Haines, 2001). As threshold $\Delta \psi$ appears to be critical for the $\mathrm{CM}$ interactions of many CAPs, including tPMP-1, even modest reductions in $\Delta \psi$ can greatly affect such interactions (Koo et al., 1996a, b, 1997; Yeaman et al., 1998; Bayer et al., 2006).

In the context of these observations, the current investigation focused on two themes: characterizing CM PL content and distribution in an isogenic $S$. aureus strain pair differing in their in vitro susceptibility profiles to tPMP-1; and delineating the effects of these parameters on net $\mathrm{CM}$ charge and peptide binding. It is relevant to mention that even small changes in CM composition can have relatively large effects upon CM function and interaction with $\mathrm{CM}$-active peptides (Lohner \& Blondelle, 2005; Pokorny \& Almeida, 2005). For example, Pokorny \& Almeida (2005) recently showed that $\delta$-lysin (a S. aureus-derived cytotoxic $\alpha$-helical peptide) interacted with small disordered model membrane domains, rather than ordered (lipid raft) domains. Importantly, a small change of the molar fraction of selected lipids (e.g. 5-10\%) significantly shifted the CM state of order, directly affecting the relative binding affinities of $\delta$-lysin.

Several interesting observations emerged from our studies. In terms of overall PL composition, no substantial differences were noted in comparing the PPMP $^{\mathrm{S}}{ }^{\mathrm{S}}$ vs tPMP- $1^{\mathrm{R}}$ strains (e.g. ISP479C vs ISP479R). However, in investigating the transbilayer PL distribution, all three PLs were found to be asymmetrically distributed within the $S$. aureus CM in both strains (Angeletti \& Nichols, 1998; Balasubramanian \& Gupta, 1996; Dixit \& Gupta, 1998; Gallet et al., 1995, 1997; McIntyre \& Sleight, 1991; Petit et al., 1992, 1994; Pomorski et al., 1996). Asymmetric PL distribution, a well-defined phenotype in eukaryotic CMs, has pivotal biological impacts (e.g. in CM stability, intercellular recognition and signal transduction: Diaz \& Schroit, 1996; Hakomori, 2003; Kol et al., 2002; Pomorski et al., 2004; Tannert et al., 2003). By contrast, positively charged aminophospholipids (particularly phosphatidylserine) are preferentially oriented in the inner CM leaflet of eukaryotes under normal physiological conditions (Balasubramanian \& Gupta, 1996; Cerbon \& Calderon 1995; Dixit \& Gupta, 1998). However, during microenvironmental shifts, this latter PL can translocate to the outer $\mathrm{CM}$ leaflet, where it plays an essential role in such diverse processes as blood coagulation, ageing, apoptosis, membrane fusion and cell-cell recognition (reviewed by Diaz \& Schroit, 1996; Fadok et al., 2000; Lentz, 2003; Pomorski et al., 2004; Tannert et al., 2003).

It is of particular interest that not only was asymmetric PL distribution common to both study strains, but distinct differences were observed in comparing the parental tPMP$1^{\mathrm{S}}$ and tPMP- $1^{\mathrm{R}}$ constructs. For LPG (the positively charged
PL species found uniquely in $S$. aureus), the majority of this PL was distributed within the inner CM leaflet. However, the tPMP- $1^{\mathrm{R}}$ construct, ISP479R, exhibited $\sim 47 \%$ more outerleaflet LPG than the tPMP- $1^{\mathrm{S}}$ parent, ISP479C, as well as the snoD-complemented variant (Table 1; Fig. 1b). Such asymmetry differences likely enhance the relative net positivity of the CM surface charge of ISP479R, and might potentially contribute to the reduced tPMP-1 susceptibility phenotype of this strain by a charge repulsion mechanism (Peschel, 2002; Peschel et al., 1999, 2001). Data from the cytochrome $c$ and poly-L-lysine binding assays support this notion, as the tPMP- $1^{\mathrm{R}}$ construct bound substantially smaller amounts of these cationic molecules than its tPMP- ${ }^{\mathrm{S}}$ parent (Fig. 4). Our peptide-binding studies further clarified this latter concept. Using the tPMP-1 synthetic analogue RP-1, and hNP-1 (both cationic peptides, having net charges of +8 and +4 respectively), we showed that relative binding of these peptides to the whole cell envelope was decreased in ISP479R as compared with ISP479C (Fig. 5). Similarly, using model liposomal membranes constructed to reflect the range of PL profiles of whole $S$. aureus cells, increasing LPG content led to substantial reductions in binding of cytochrome $c$, poly-L-lysine, RP-1, tPMP-1 and hNP-1 (Figs 6 and 7). These data provide support for the idea that differences in interaction of tPMP-1 with the target cell surface envelope and CM are major determinants of tPMP-1 susceptibility profile differences between tPMP $^{\mathrm{S}}{ }^{\mathrm{S}}$ and tPMP- $1^{\mathrm{R}}$ strains. It should also be pointed out that, in addition to differences in envelope and/or CM charge, the intrinsic $\Delta \psi$ influences the interaction of cationic molecules such as tPMP-1 with the CM, and their subsequent transmembrane passage (Koo et al., 1996a, b, 1999; Yeaman et al., 1998).

Additionally, an asymmetric distribution for CL was documented, preferentially within the outer $\mathrm{CM}$ leaflet for both strains. As above for LPG and PG, strain ISP479R demonstrated a difference in its CL asymmetry vs strain ISP479C, with relatively less CL $(\sim 10 \%)$ in its outer CM leaflet. Importantly, CL can serve as a proton reservoir and cap for the $\mathrm{CM} \mathrm{F}_{0}-\mathrm{F}_{1}$ ATPase proton gradient system (Kates et al., 1993). Thus, CL contributes to $\Delta \psi$ generation, and reduced amounts of CL (i.e. as in the ISP479R outer CM leaflet) could contribute to the altered $\Delta \psi$ phenotype of this latter strain.

Several recent studies have characterized lipid and PL translocases in Escherichia coli and Salmonella typhimurium (Doerrler et al., 2004; Kol et al., 2003, 2004; Polissi \& Georgopoulos, 1996; Reyes \& Chang, 2005). Among Grampositives, only Lactococcus lactis has been shown to possess a gene $(\operatorname{lm} r A)$ encoding an $\mathrm{ABC}$ transporter involved in transport of amphiphilic drugs, as well as fluorescent lipid analogues, across the CM (Margolles et al., 1999). Our current data suggest that $S$. aureus possesses translocases for each of the major CM PLs. Interestingly, work by A. Peschel and co-workers has recently suggested that one domain of the $m p r F$ operon encoding PG lysinylation may be 
functioning as an LPG translocase (unpublished data). The genetic linkage between the snoD mutation in ISP-479R and the enhanced LPG translocation and increased membrane fluidity in this construct is not known at this time. Since the snoD mutation disrupts a complex I enzyme gene (an NADH-oxidoreductase maximally active under microaerophilic or anaerobic conditions), it is conceivable that these two distinct membrane adaptations are part of a coordinated response to an altered redox state. We are currently investigating this issue.

As ISP479 background strains are partially deficient in the function of the $\operatorname{sig} B$ stress-response operon (Horsburgh et al., 2002), current studies are ongoing in our laboratories to examine PL profiles and asymmetry in other tPMP- $1^{\mathrm{s}}$ vs tPMP- $1^{\mathrm{R}}$ strain pairs of sigB-intact genetic backgrounds. This will enable us to understand the role of $\operatorname{sig} B$ in the regulation of overall PL composition and asymmetry. Finally, our laboratories are also investigating potential contributions of CM fatty acid profiles to tPMP-1 susceptibility phenotypes.

\section{ACKNOWLEDGEMENTS}

This research was supported by grants from the National Institutes of Health (AI053235-01 to P. J.M; AI42072 to R.A.P., AI-39108 to A.S.B. and AI-48031 to M.R.Y.), and from the American Heart Association (0265054Y to Y.Q.X).

\section{REFERENCES}

Angeletti, C. \& Nichols, J. W. (1998). Dithionite quenching rate measurement of the inside-outside membrane bilayer distribution of 7-nitrobenz-2-oxa-1,3-diazol-4-yl-labeled phospholipids. Biochemistry 37, 15114-15119.

Balasubramanian, K. \& Gupta, C. M. (1996). Transbilayer phosphatidylethanolamine movements in yeast plasma membranes. Evidence for protein-mediated, energy-dependent mechanism. Eur J Biochem 240, 798-806.

Balch, C., Morris, R., Brooks, E. \& Sleight, R. G. (1994). The use of $N$-(7-nitrobenz-2-oxa-1,3-diazole-4-yl)-labeled lipids in determining transmembrane lipid distribution. Chem Phys Lipids 70, 205-212.

Bates, D. M., von Eiff, C., McNamara, P. J., Peters, G., Yeaman, M. R., Bayer, A. S. \& Proctor, R. A. (2003). Staphylococcus aureus menD and hemB mutants are as infective as the parent strains, but the menadione biosynthetic mutant persists within the kidney. I Infect Dis 187, 1654-1661.

Bayer, A. S., Cheng, D., Yeaman, M. R., Corey, G. R., McClelland, R. S., Harrel, L. J. \& Fowler, V. G., Jr (1998). In vitro resistance to thrombin-induced platelet microbicidal protein among clinical bacteremic isolates of Staphylococcus aureus correlates with an endovascular infectious source. Antimicrob Agents Chemother 42, 3169-3172.

Bayer, A. S., Prasad, R., Chandra, J., Koul, A., Smriti, M., Varma, A., Skurray, R. A., Firth, N., Brown, M. H. \& other authors (2000). In vitro resistance of Staphylococcus aureus to thrombin-induced platelet microbicidal protein is associated with alterations in cytoplasmic membrane fluidity. Infect Immun 68, 3548-3553.

Bayer, A. S., McNamara, P., Yeaman, M. R., Lucindo, N., Jones, T., Cheung, A. L., Sahl, H. G. \& Proctor, R. A. (2006). Transposon disruption of the complex I NADH oxidoreductase gene (snoD) in Staphylococcus aureus is associated with reduced susceptibility to the microbicidal activity of thrombin-induced platelet microbicidal protein 1. J Bacteriol 188, 211-222.

Brogden, K. A. (2005). Antimicrobial peptides: pore formers or metabolic inhibitors in bacteria? Nat Rev Microbiol 3, 238-250.

Cerbon, J. \& Calderon, V. (1995). Generation, modulation and maintenance of the plasma membrane asymmetric phospholipid composition in yeast cells during growth: their relation to surface potential and membrane protein activity. Biochim Biophys Acta 1235, 100-106.

Dekkers, D. W., Comfurius, P., van Gool, R. G., Bevers, E. M. \& Zwaal, R. F. (2000). Multidrug resistance protein 1 regulates lipid asymmetry in erythrocyte membranes. Biochem J 350, 531-535.

Dhawan, V. K., Yeaman, M. R., Cheung, A. L., Kim, E., Sullam, P. M. \& Bayer, A. S. (1997). Phenotypic resistance to thrombin-induced platelet microbicidal protein in vitro is correlated with enhanced virulence in experimental endocarditis due to Staphylococcus aureus. Infect Immun 65, 3293-3299.

Diaz, C. \& Schroit, A. J. (1996). Role of translocases in the generation of phosphatidylserine asymmetry. J Membr Biol 151, 1-9.

Dixit, B. L. \& Gupta, C. M. (1998). Role of the actin cytoskeleton in regulating the outer phosphatidylethanolamine levels in yeast plasma membrane. Eur J Biochem 254, 202-206.

Doerrler, W. T., Gibbons, H. S. \& Raetz, C. R. (2004). MsbAdependent translocation of lipids across the inner membrane of Escherichia coli. J Biol Chem 279, 45102-45109.

Dogra, S., Krishnamurthy, S., Gupta, V., Dixit, B. L., Gupta, C. M., Sanglard, D. \& Prasad, R. (1999). Asymmetric distribution of phosphatidylethanolamine in $C$. albicans: possible mediation by CDR1, a multidrug transporter belonging to ATP binding cassette (ABC) superfamily. Yeast 15, 111-121.

Fadok, V. A., Bratton, D. L., Rose, D. M., Pearson, A., Ezekewitz, R. A. \& Henson, P. M. (2000). A receptor for phosphatidylserine-specific clearance of apoptotic cells. Nature 405, 85-90.

Fowler, V. G., Jr, McIntyre, L. M., Yeaman, M. R., Peterson, G. E., Barth Reller, L., Corey, G. R., Wray, D. \& Bayer, A. S. (2000). In vitro resistance to thrombin-induced platelet microbicidal protein in isolates of Staphylococcus aureus from endocarditis patients correlates with an intravascular device source. J Infect Dis 182, 1251-1254.

Gallet, P. F., Maftah, A., Petit, J. M., Denis-Gay, M. \& Julien, R. (1995). Direct cardiolipin assay in yeast using the red fluorescence emission of 10- $N$-nonyl acridine orange. Eur J Biochem 228, 113-119.

Gallet, P. F., Petit, J. M., Maftah, A., Zachowski, A. \& Julien, R. (1997). Asymmetrical distribution of cardiolipin in yeast inner mitochondrial membrane triggered by carbon catabolite repression. Biochem J 324, 627-634.

Grant, A. M., Hanson, P. K., Malone, L. \& Nichols, J. W. (2001). NBDlabeled phosphatidylcholine and phosphatidylethanolamine are internalized by transbilayer transport across the yeast plasma membrane. Traffic 2, 37-50.

Haines, T. H. (2001). Do sterols reduce proton and sodium leaks through lipid bilayers? Prog Lipid Res 40, 299-324.

Hakomori, S. (2003). Structure, organization, and function of glycosphingolipids in membrane. Curr Opin Hematol 10, 16-24.

Horsburgh, M. J., Aish, J. L., White, I. J., Shaw, L., Lithgow, J. K. \& Foster, S. J. (2002). Sigma B modulates virulence determinant expression and stress resistance: characterization of a functional $r s b U$ strain derived from Staphylococcus aureus 8325-4. J Bacteriol 184, 5457-5467. 
Hrafnsdottir, S., Nichols, J. W. \& Menon, A. K. (1997). Transbilayer movement of fluorescent phospholipids in Bacillus megaterium membrane vesicles. Biochemistry 36, 4969-4978.

Huijbregts, R. P., de Kroon, A. I. \& de Kruijff, B. (1998). Rapid transmembrane movement of newly synthesized phosphatidylethanolamine across the inner membrane of Escherichia coli. J Biol Chem 273, 18936-18942.

Kates, M., Syz, J. Y., Gosser, D. \& Haines, T. H. (1993). pHdissociation characteristics of cardiolipin and its $2^{\prime}$-deoxy analogue. Lipids 28, 877-882.

Kol, M. A., de Kruijff, B. \& de Kroon, A. I. (2002). Phospholipid flipflop in biogenic membranes: what is needed to connect opposite sides. Semin Cell Dev Biol 13, 163-170.

Kol, M. A., van Dalen, A., de Kroon, A. I. \& de Kruijff, B. (2003). Translocation of phospholipids is facilitated by a subset of membrane-spanning proteins of the bacterial cytoplasmic membrane. J Biol Chem 278, 24586-24593.

Kol, M. A., de Kroon, A. I., Killian, J. A. \& de Kruijff, B. (2004). Transbilayer movement of phospholipids in biogenic membranes. Biochemistry 43, 2673-2681.

Koo, S. P., Bayer, A. S., Sahl, H. G., Proctor, R. A. \& Yeaman, M. R. (1996a). Staphylocidal action of thrombin-induced platelet microbicidal protein is not solely dependent on transmembrane potential. Infect Immun 64, 1070-1074.

Koo, S. P., Yeaman, M. R. \& Bayer, A. S. (1996b). Staphylocidal action of thrombin-induced platelet microbicidal protein is influenced by microenvironment and target cell growth phase. Infect Immun 64, 3758-3764.

Koo, S. P., Yeaman, M. R., Nast, C. C. \& Bayer, A. S. (1997). The cytoplasmic membrane is a primary target for the staphylocidal action of thrombin-induced platelet microbicidal protein. Infect Immun 65, 4795-4800.

Koo, S.-P., Kagan, B. L., Bayer, A. S. \& Yeaman, M. R. (1999). Membrane permeabilization by thrombin-induced platelet microbicidal protein- 1 is modulated by transmembrane voltage orientation and magnitude. Infect Immun 67, 2475-2481.

Koo, S.-P., Bayer, A. S. \& Yeaman, M. R. (2001). Diversity in antistaphylococcal mechanisms among membrane-targeting antimicrobial peptides. Infect Immun 69, 4916-4922.

Koprivnjak, T., Peschel, A., Gelb, M. H., Liang, N. S. \& Weiss, J. P. (2002). Role of charge properties of bacterial envelope in bactericidal action of human group IIA phospholipase A2 against Staphylococcus aureus. J Biol Chem 277, 47636-47644.

Kristian, S. A., Lauth, X., Nizet, V., Goetz, F., Neumeister, B., Peschel, A. \& Landmann, R. (2003). Alanylation of teichoic acids protects Staphylococcus aureus against Toll-like receptor 2-dependent host defense in a mouse tissue cage infection model. J Infect Dis 188, 414-423.

Kupferwasser, L. I., Skurray, R. A., Brown, M. H., Firth, N., Yeaman, M. R. \& Bayer, A. S. (1999). Plasmid-mediated resistance to thrombin-induced platelet microbicidal protein in staphylococci: role of the qacA locus. Antimicrob Agents Chemother 43, 2395-2399.

Kupferwasser, L. I., Yeaman, M. R., Shapiro, S. M., Nast, C. C. \& Bayer, A. S. (2002). In vitro susceptibility to thrombin-induced platelet microbicidal protein is associated with reduced disease progression and complication rates in experimental Staphylococcus aureus endocarditis: microbiological, histopathologic, and echocardiographic analyses. Circulation 105, 746-752.

Lentz, B. R. (2003). Exposure of platelet membrane phosphatidylserine regulates blood coagulation. Prog Lipid Res 42, 423-438.

Lohner, K. \& Blondelle, S. E. (2005). Molecular mechanisms of membrane perturbation by antimicrobial peptides and the use of biophysical studies in the design of novel peptide antibiotics. Comb Chem High Throughput Screen 8, 241-256.

Margolles, A., Putman, M., van Veen, H. W. \& Konings, W. N. (1999). The purified and functionally reconstituted multidrug transporter LmrA of Lactococcus lactis mediates the transbilayer movement of specific fluorescent phospholipids. Biochemistry 38, 16298-16306.

McIntyre, J. C. \& Sleight, R. G. (1991). Fluorescence assay for phospholipid membrane asymmetry. Biochemistry 30, 11819-11827.

Moore, R. A., Bates, N. C. \& Hancock, R. E. (1986). Interaction of polycationic antibiotics with Pseudomonas aeruginosa lipopolysaccharide and lipid A studied by using dansyl-polymyxin. Antimicrob Agents Chemother 29, 496-500.

Nishi, H., Komatsuzawa, H., Fujiwara, T., McCallum, N. \& Sugai, M. (2004). Reduced content of lysyl-phosphatidylglycerol in the cytoplasmic membrane affects susceptibility to moenomycin, as well as vancomycin, gentamicin, and antimicrobial peptides, in Staphylococcus aureus. Antimicrob Agents Chemother 48, 4800-4807.

Peschel, A. (2002). How do bacteria resist human antimicrobial peptides? Trends Microbiol 10, 179-186.

Peschel, A., Otto, M., Jack, R. W., Kalbacher, H., Jung, G. \& Gotz, F. (1999). Inactivation of the dlt operon in Staphylococcus aureus confers sensitivity to defensins, protegrins, and other antimicrobial peptides. J Biol Chem 274, 8405-8410.

Peschel, A., Jack, R. W., Otto, M., Collins, L. V., Staubitz, P., Nicholson, G., Kalbacher, H., Nieuwenhuizen, W. F., Jung, G. \& other authors (2001). Staphylococcus aureus resistance to human defensins and evasion of neutrophil killing via the novel virulence factor MprF is based on modification of membrane lipids with $\mathrm{L}-$ lysine. J Exp Med 193, 1067-1076.

Petit, J. M., Maftah, A., Ratinaud, M. H. \& Julien, R. (1992). 10Nnonyl acridine orange interacts with cardiolipin and allows the quantification of this phospholipid in isolated mitochondria. Eur J Biochem 209, 267-273.

Petit, J. M., Huet, O., Gallet, P. F., Maftah, A., Ratinaud, M. H. \& Julien, R. (1994). Direct analysis and significance of cardiolipin transverse distribution in mitochondrial inner membranes. Eur J Biochem 220, 871-879.

Pokorny, A. \& Almeida, P. F. (2005). Permeabilization of raftcontaining lipid vesicles by delta-lysin: a mechanism for cell sensitivity to cytotoxic peptides. Biochemistry 44, 9538-9544.

Polissi, A. \& Georgopoulos, C. (1996). Mutational analysis and properties of the $m s b A$ gene of Escherichia coli, coding for an essential ABC family transporter. Mol Microbiol 20, 1221-1233.

Pomorski, T., Muller, P., Zimmermann, B., Burger, K., Devaux, P. F. \& Herrmann, A. (1996). Transbilayer movement of fluorescent and spin-labeled phospholipids in the plasma membrane of human fibroblasts: a quantitative approach. J Cell Sci 109, 687-698.

Pomorski, T., Holthuis, J. C., Herrmann, A. \& van Meer, G. (2004). Tracking down lipid flippases and their biological functions. $J$ Cell Sci 117, 805-813.

Reyes, C. L. \& Chang, G. (2005). Structure of the ABC transporter MsbA in complex with ADP.vanadate and lipopolysaccharide. Science 308, 1028-1031.

Rossetti, F. F., Reviakine, I., Csúcs, G., Assi, F., Vörös, J. \& Textor, M. (2004). Interaction of poly(L-lysine)-g-poly(ethylene glycol) with supported phospholipid bilayers. Biophys J 87, 1711-1721.

Satchell, D. P., Sheynis, T., Shirafuji, Y., Kolusheva, S., Ouellette, A. J. \& Jelinek, R. (2003). Interactions of mouse Paneth cell $\alpha$-defensins and $\alpha$ defensin precursors with membranes. Prosegment inhibition of peptide association with biomimetic membranes. J Biol Chem 278, 13838-13846.

Takemura, H., Kaku, M., Kohno, S., Hirakata, Y., Tanaka, H., Yoshida, R., Tomono, K., Koga, H., Wada, A. \& other authors (1996). 
Evaluation of susceptibility of gram-positive and -negative bacteria to human defensins by using radial diffusion assay. Antimicrob Agents Chemother 40, 2280-2284.

Tannert, A., Pohl, A., Pomorski, T. \& Herrmann, A. (2003). Proteinmediated transbilayer movement of lipids in eukaryotes and prokaryotes: the relevance of $\mathrm{ABC}$ transporters. Int $J$ Antimicrob Agents 22, 177-187.

Wu, T., Yeaman, M. R. \& Bayer, A. S. (1994). In vitro resistance to platelet microbicidal protein correlates with endocarditis source among bacteremic staphylococcal and streptococcal isolates. Antimicrob Agents Chemother 38, 729-732.

Xiong, Y. Q., Yeaman, M. R. \& Bayer, A. S. (1999). In vitro antibacterial activities of platelet microbicidal protein and neutrophil defensin against Staphylococcus aureus are influenced by antibiotics differing in mechanism of action. Antimicrob Agents Chemother 43, 1111-1117.

Xiong, Y. Q., Bayer, A. S. \& Yeaman, M. R. (2002). Inhibition of intracellular macromolecular synthesis in Staphylococcus aureus by thrombin-induced platelet microbicidal proteins. J Infect Dis 185, 348-356.

Xiong, Y. Q., Mukhopadhyay, K., Yeaman, M. R., Adler-Moore, J. \& Bayer, A. S. (2005). Functional interrelationships between cell membrane and cell wall in antimicrobial peptide-mediated killing of Staphylococcus aureus. Antimicrob Agents Chemother 49, 3114-3121.

Xiong, Y. Q., Bayer, A. S., Elazegui, L. \& Yeaman, M. R. (2006). A synthetic congener modeled on a microbicidal domain of thrombininduced platelet microbicidal protein-1 recapitulates staphylocidal mechanisms of the native molecule. Antimicrob Agents Chemother 50, 3786-3792.

Yeaman, M. R. (1997). The role of platelets in antimicrobial host defense. Clin Infect Dis 25, 951-968.

Yeaman, M. R. \& Yount, N. Y. (2003). Mechanisms of antimicrobial peptide action and resistance. Pharmacol Rev 55, 27-55.

Yeaman, M. R., Sullam, P. M., Dazin, P. F. \& Bayer, A. S. (1994). Platelet microbicidal protein alone and in combination with antibiotics reduces Staphylococcus aureus adherence to platelets in vitro. Infect Immun 62, 3416-3423.

Yeaman, M. R., Tang, Y. Q., Shen, A. J., Bayer, A. S. \& Selsted, M. E. (1997). Purification and in vitro activities of rabbit platelet microbicidal proteins. Infect Immun 65, 1023-1031.

Yeaman, M. R., Bayer, A. S., Koo, S. P., Foss, W. \& Sullam, P. M. (1998). Platelet microbicidal proteins and neutrophil defensin disrupt the Staphylococcus aureus cytoplasmic membrane by distinct mechanisms of action. J Clin Invest 101, 178-187.

Yeaman, M. R., Gank, K. D., Bayer, A. S. \& Brass, E. P. (2002). Synthetic peptides that exert antimicrobial activities in whole blood and blood-derived matrices. Antimicrob Agents Chemother 46, 3883-3891.

Yount, N. Y., Gank, K. D., Xiong, Y. Q., Bayer, A. S., Pender, T., Welch, W. H. \& Yeaman, M. R. (2004). Platelet microbicidal protein 1: structural themes of a multifunctional antimicrobial peptide. Antimicrob Agents Chemother 48, 4395-4404.

Edited by: W. B. van Leeuwen 